\title{
Politician's Strategic Impression Management on Instagram
}

\author{
Younbo Jung \\ Nanyang Technological Univ. \\ ybjung@ntu.edu.sg \\ Judith Ho \\ Nanyang Technological Univ. \\ jho2@e.ntu.edu.sg
}

\author{
Ashley Tay \\ Nanyang Technological Univ. \\ atay1@e.ntu.edu.sg \\ Yan Hui Goh \\ Nanyang Technological Univ. \\ YHGOH1@e.ntu.edu.sg
}

\author{
Terence Hong \\ Nanyang Technological Univ. \\ jkheng1@e.ntu.edu.sg
}

\begin{abstract}
With the growing trend of Instagram usage among politicians, this study investigates the effects of two self-presentation styles of personalization (i.e. presenting the private over the public life of a politician) and interactivity (i.e. presenting the active versus passive voice of a politician) on voters' perception of politicians and their voting intention in the context of Instagram. The results of an experiment $(n=120)$ showed that presenting the public life of a politician had a more positive effect on perception of character, compared to the private life. Using a highly interactive style on Instagram had a more positive effect on perception of character, compared to a lack of interactivity. Finally, character perception was found to be a mediator for the effects of personalization and interactivity on voting intention. Theoretical implications with respect to impression management on social media, as well as practical implications for political engagement, are discussed.
\end{abstract}

\section{Introduction}

Singapore has the world's second highest social media penetration rate at 59\% [1]. Younger Singaporeans are spending more time on social media, and $60-70 \%$ of them use social media to give feedback or share their opinions about the government or local politics [2]. In March 2010, the Singapore Parliament lifted a ban on Internet campaigning, making the 2011 General Elections the first time online platforms were used in political campaigns [3]. Hence, all political parties in Singapore used social media, such as Facebook and Twitter, in their campaigning for the 2011 elections. Social media facilitates communication between politicians and the electorate [4]; and directs voters to party websites and personal blogs [5]. Although there is extensive research investigating politicians' use of social media like Facebook and Twitter, relatively fewer empirical studies on Instagram.

This study aims to contribute to research on Instagram, and to investigate how politicians' usage of Instagram could influence first-time voters who tend to be more comfortable with the use of social media. To meet these aims, we looked at two selfpresentation styles of politicians on Instagram (i.e., personalization and interactivity) to investigate how these strategies influence perceived character traits of politicians and voting intention among voters.

\section{Literature Review}

Instagram is an uprising, photo-based social media platform, with its share of social sites visits growing 8,121\% between July 2011 and July 2012 in Singapore [6]. It is now the most popular social network among teens [7]. As of February 2014, 15 of Singapore's 99 Members of Parliament (MP) have created their own Instagram accounts. These Instagram accounts allow politicians to control the content posted of themselves, and may help in managing the public's impression of them more effectively.

\subsection{Impression management on Instagram}

Politicians constantly engage in political impression management to improve the perceptions they portray to the audience [8]. Studies on social media platforms like Facebook and Twitter have shown that the Internet can provide a platform for politicians to present the best version of themselves to the electorate [9], to manage a variety of impressions [10], and to promote themselves [11].

To further understand how politicians are currently using Instagram, we conducted a content analysis of ten Singaporean and foreign politicians. Through this, we observed a public-private dichotomy from their presentation styles. For 
example, Singaporean politicians like MP Baey Yam Keng and Teo Ser Luck upload photos on their private lives, while Prime Minister Lee Hsien Loong focuses on his daily activities of his public life as prime minister.

Although Instagram is a predominantly visual platform, we observed how captions gave context to the pictures and could lend a personal voice to the politicians. Some politicians gave short and curt captions, while others gave lengthier captions, conveying the voice of the politician more clearly and intimately.

Hence, based on the literature review on impression management and our content analysis, we chose two impression management styles to focus on - personalization and interactivity.

\subsection{Personalization of politicians}

Previous research found that politicians are increasingly being portrayed as individuals in the news [12], and are revealing private details related to the politicians' lifestyle [13]. Such presentation of the "human" persona is even considered necessary to achieve political and electoral success [14]. MP Baey Yam Keng said that his Instagram photos helped him to relate better to people, especially the youth, and that such Instagram photos help to show that MPs are also human [14].

Many researchers have studied the effects of this focus on the portrayal of a politician's private life, which includes their lifestyle, upbringing, religion, personal appearance, health, romantic relationships, and even financial situation $[12,15]$. An emphasis on the politicians" "human" side may positively improve the voters' judgement of these politicians by bringing the politicians closer to voters, making them appear personable and familiar to voters $[13,15]$.

Due to the lack of gatekeepers, a politician can upload photos by himself, and portray himself at an even more personal level on Instagram than in traditional media. Hence, we aim to find its effects in the context of Instagram and in the local setting of Singapore. Hence, we propose the following hypothesis:

H1: Depiction of a politician's private life on Instagram will lead to (a) a more positive character evaluation of the politician; and (b) a greater intention to vote for the politician.

\subsection{Interactivity}

There have been many proposed definitions and operationalization of interactivity. An often cited definition is McMillan's three types of interactivity: user-to-system, user-to-document, and lastly, user-touser [16]. Other researchers have split interactivity into two types: media interactivity and human interactivity. Media interactivity explains interactivity through the functional features of the medium itself [17]. The other type, human interactivity looks at interactivity between users [18]. Interactivity has been seen to lead to a more positive character perception [17] and increased voting intention [19].

In our study's context of Instagram, we conceptualized interactivity as defined in Endres and Warnick's text-based interactivity, which mostly concerns itself with non-reciprocal forms of interaction [20], and included the presence of replies to followers,. Text-based interactivity makes use of stylistic devices such as first-person address, the use of active or passive voice, and in-situ photos of the media figure, etc. to achieve a high level of interactivity [21]. To achieve text-based interactivity in one's communication, the audience should get a sense of the voice of the communicator [20], as though the politician is in an actual two-way dialogue with his audience. Endres and Warnick state that the use of first person address and an active voice is important to convey the "personal presence" of a politician (p335) [20]. Non-reciprocal interactivity is similar to what was identified by Horton and Wohl in their theory of parasocial interactivity, which has been termed as "intimacy at a distance" (p 215) [21].

Politicians may tend to avoid the use of true twoway user-to-user interaction with their hundreds of followers as it can be burdensome, and difficult to manage. Hence, politicians may not be taking full advantage of social media's capabilities for two-way communication. However, a study by Lee \& Shin found that reading the verbal exchanges of a politician and other followers is enough to provide the perception of vicarious participation in the (virtual) interaction [19].

Few studies have examined the effects of nonreciprocal interactivity on character evaluations of a politician and voting intention. Hence, we are interested to find if the positive effects of the other forms of interactivity on character evaluation and voting intention extend to our conceptualization of non-reciprocal interactivity as well.

H2: Greater interactivity displayed by the politician on Instagram will lead to (a) a more positive character evaluation of the politician; and (b) a greater intention to vote for the politician. 


\subsection{Perceived character traits as psychological mechanisms for impression management}

Character traits of a politician have shown to produce a significant influence on voter choice [22], and it was found to be the strongest and most stable predictor of voters' choices [23]. Previous literature suggests that personalization and interactivity may help the electorate attribute positive character traits to politicians, as well as increase voting intention. When viewed together, it is reasonable to argue that perceived character traits may mediate the effects of personalization and interactivity on voting intention.

H3: The effects of personalisation and interactivity on the intention to vote for $a$ politician, is mediated by voters' evaluation of a politician's character traits.

\section{Method}

\subsection{Experimental design}

Our participants consisted of 120 Singaporean undergraduates ( $49.2 \%$ male and $50.8 \%$ female), with ages ranging from 18 to $24(M=21.6, S D=1.17)$. The experiment had a $2 \times 2$ between-subject design, with two levels of personalization and interactivity each. Each participant was randomly assigned to one of the four conditions hosted on a public web domain in the university's computer laboratory. Participants read the instructions and cover story, before viewing the pictures and completing the online survey. A mock Instagram account, designed to be as realistic as possible, was created for the experiment, and participants were told that the account belonged to a politician running in the 2016 Singapore General Elections.

\subsection{Manipulation}

For personalization, two sets of pictures were created, with the low personalization conditions consisting of pictures that featured the politician in a public setting, such as him participating in grassroots activities and discussing public issues. Participants who were assigned to the high personalization conditions were shown pictures of the politician in a private setting, including photos of the politician's family and hobbies.

The levels of interactivity in the experiment were manipulated through the stylistic devices discussed in Warnick et al.’s [21] text-based interactivity and the use of replies to followers. The high interactivity conditions contained picture captions using first person pronouns, direct address, active voice, and replies to commenters. The low interactivity conditions consisted of picture captions with a lack of first person pronouns, direct address, and replies to commenters. Care was taken to ensure that despite the differences in tone of captions and stylistic devices used, they remained similar in both length and meaning.

\subsection{Measures}

The measure of the character traits of the politician was obtained through 24 items modified from Benoit and McHale's four dimensions of personal qualities: sincerity, morality, empathy and drive [24], along with four other separate traits of charisma, humility, thriftiness and reasonable that Benoit and McHale identified. We also added an additional dimension of competency to our measurement. This adapted index consisted of items such as "this politician is a man of integrity," and "this politician is competent", and was measured on a five-point Likert scale, from strongly disagree to strongly agree, where a higher score would mean a more positive impression of the politician (Cronbach alpha $=.89$ ).

The intention to vote for the politician was measured using three items adapted from Lee and $\mathrm{Oh}^{59}$. The questions were: "I would like this politician to run in the next elections," "I would vote for this candidate in the next election," and "I would support this candidate in the next election." Responses were measured using a five-point Likert scale from strongly disagree to strongly agree. A higher score means that the participant is more willing to support and vote for the politician (Cronbach alpha $=.88)$.

\section{Results}

A two-way between-subject Analysis of Variance (ANOVA) was used to test the main effect of personalization (H1) and interactivity (H2) on perceived character traits and voting intention. A bootstrapping analysis was also used to examine the mediation effect of perceived character traits (H3).

\subsection{Personalization on Instagram}

There was a significant main effect of personalization on the perceived character traits, $F(3$, 116) $=9.17, p<.00, \eta^{2}=.07$. However, contrary to 
what was hypothesized, participants exposed to the public life of a politician reported a more positive perception of the politician's character $(M=3.54, S D$ $=.29$ ), compared to the participants exposed to the private life of a politician $(M=3.36, S D=.34)$. Hence, H1a was not supported.

In contrary to $\mathrm{H} 1 \mathrm{~b}$, there was no significant effect of personalization on voting intention, $F(3,116)=$ .17 , n.s. Participants exposed to the private setting on Instagram $(M=2.99, S D=.52)$ did not significantly differ in their voting intention from participants exposed to the public setting on Instagram $(M=3.03$, $S D=.54)$. Therefore, H1b was not supported.

\subsection{Interactivity on Instagram}

There was a significant main effect of interactivity on perceived character traits of the politician, $F(3,116)=3.87, p=.05, \eta^{2}=.03$. Participants exposed to the high interactivity condition rated the politician more positively $(M=$ 3.51, $S D=.34)$, compared to the participants exposed to the low interactivity condition $(M=3.39, S D=$ .31). Hence, H2a was supported.

On the other hand, here was no significant effect of interactivity on voting intention, $F(3,116)=.03$, n.s. There was no significant difference between participants exposed to the high interactivity condition $(M=3.00, S D=.52)$ and participants exposed to the low interactivity condition $(M=3.02$, $S D=.54)$. Thus, H2b was not supported.

\subsection{Interaction effect on voting intention}

Despite the lack of main effects from personalization and interactivity on voting intention, there was a marginally significant interaction effect from the two independent variables, $F(3,116)=3.66$, $p=.058, \eta^{2}=.03$. As can be seen from Appendix F, participants who were exposed to the politician's public life, coupled with high interactivity, were the most inclined to vote for the politician. Participants who were exposed to the condition with low interactivity and the depiction of the politician's private life had the second highest voting intention. On the other hand, participants who were exposed to the public and low interactivity condition and the private and high interactivity condition reported relatively less intention to vote for the politician.

\subsection{Mediation effect of character traits on voting intention}

The mediating effect of character traits was analyzed using the single step mediation model ${ }^{60}$, testing if the effects of personalization and interactivity on voting intention would be mediated by perceived character traits. The bootstrap analysis would allow for greater statistical power while controlling for possible Type 1 errors $^{60}$.

The bootstrap results for indirect effects showed that perceived character traits was a successful mediator for the effects of personalization and interactivity on voting intention (95\% CI $=[.0307$ $0.2580] ; \quad C I=[-.1734 \sim-.0064]$, respectively), confirming H3. Approximately $12.9 \%$ of the variance in voting intention can be explained by the linear combination of personalization, interactivity and perceived character traits.

\section{Discussion}

\subsection{Character Traits}

Contrary to what was hypothesized about personalization, it was the portrayal of the politician's public life on Instagram that led to a higher rating for perceived character traits. This could be due to the cultural differences between Singapore and other Western countries, where more politicians are using and benefitting from the portrayal of their private life as a political strategy $[13,15]$. According to Hofstede's dimensions of culture, Singapore scores as a collectivistic culture [25]. Hence, we posit three reasons for the opposite results. Firstly, in a collectivistic culture, individuals see themselves as part of a larger community, and the needs of the community take precedence over individual needs. In our study, the display of photos of a politician's private life may position the politician as an individual, separate from the community. Secondly, in a collectivistic culture, individual achievements are seen to be a result of effort more than ability [26]. Diligence and drive are more evident in the public life photos, which show a politician at work, than the photos depicting his private life. Thirdly, Singapore also ranks high in power distance [25], suggesting that citizens are used to a hierarchical structure of power. Singaporeans may accept that politicians are in a position of power and have a role to play in public office, and prefer that the politician's self-presentation on Instagram follows this expectation. Hence the portrayal of the public life of a politician may be more in line with expectations of citizens in a collectivistic culture. More research needs to be done before any conclusions can be drawn on the effects of cultural differences. 
With respect to interactivity, the results showed that greater interactivity displayed by a politician led to more positive evaluations of his character, which is in line with previous research [19]. The results imply that the appearance of dialogic communication could induce more positive evaluations of a politician on Instagram, regardless of the existence of true twoway dialogic communication. It may be possible for a politician to occasionally reply to some followers and still be able to achieve the same sense of user-to-user interactivity, similar to what Horton and Wohl first theorized in their concept of parasocial interactivity [21].

The results also suggest that although visuals are important, politicians should not neglect the use of captions. With this result in mind, carefully written captions, together with photos, may result in more synergetic effects of impression management by politicians on Instagram.

\subsection{Voting Intention}

Inconsistent with our literature review, the results suggest that the portrayal of the public or personal persona of the politician, and the use of interactivity on social media might be insufficient in inducing voting intention. The lack of voting intention could be due to the use of a mock politician without any political affiliations. Partisan voting has been researched on, and this practice can be seen in Singapore too [26]. Political affiliations function as a mental shortcut for voting decisions when there is a lack of information [27]. Thus, in our context, there might have been insufficient information for them to come to a decision on voting for the mock politician. Future research can consider the effect of political party affiliation and its interaction with the variables of personalization and interactivity on voting intention.

Despite being unable to produce an effect on voting intention individually, our findings suggest that there were two combinations of self-presentation strategies that worked together to produce positive effects on voting intention: low personalization with high interactivity, and high personalization with low interactivity. This suggests that there needs to be a balance between personalization and interactivity to maintain an optimal distance between the politician and the electorate. The electorate may want a politician who is not too distant and detached from their lives and problems, but yet able to maintain a professional distance from them. The fear of the trivialization of politics is often associated with the issue of high level of personalisation ${ }^{32}$, and too much familiarity cultivated by electronic media may "breed contempt”, rendering the politician ordinary ${ }^{68}$. More research can be carried out in this area to confirm how personalization and interactivity work together to bridge this distance between the politician and the electorate, especially in the Singapore context

Mediation analysis showed that perceived character traits successfully mediated the effects of personalization and interactivity on voting intention. Thus, when a positive evaluation of a candidate's character is induced by low personalization and high interactivity respectively, intention to vote for the politician might follow. Singaporean politicians mainly reach out to the electorate through political rallies, were and only able to use social media starting from the 2011 elections. The use of such a new alternative strategy may not appear to have a direct effect on voting intention, but it still can be said to produce tangible effects through its indirect impact on voting intention.

\subsection{Limitation}

A possible limitation of our study could be that it only sampled a small population of first-time voters in the 2016 Singapore General Elections. Voting behavior is possibly influenced by education and socio-economic background, and replications of this experiment can include a larger sample to take into account demographic differences.

Another limitation is its experimental setting. The experiment was conducted in a simple laboratory setting with a simulated politician. In real life, there are many factors that may influence people's perception of and voting intention for politicians, as partially discussed in 5.2. In this sense, we need to be cautious not to overgeneralize the findings. However, in spite of this limitation, the current study showed that different presentation strategies on Instagram could also influence people's perception and voting intention. This additional effort of impression management on Instagram could either boost up preexisting positive images or negate negative images, depending on how people perceive politicians before virtual interaction on Instagram. Taken together, there needs more future studies that can examine generalizability and ecological validity, in addition to establishing causal effects.

Lastly, it is possible that the manipulation was not strong enough. Although we followed previous literature carefully when we operationalized personalization and interactivity, we did not conduct any systematic manipulation check because such direct manipulation check could lead participants to figure out study's true purposes. 


\section{Conclusion}

The current study demonstrated that low personalization, and high interactivity work independently to produce positive effects on character evaluation. However, these two variables were found to be able to induce voting intention as well, either indirectly: mediated by character traits; or by working in tandem. We believe that our findings centering on the presentation styles of personalization portrayed through images and the interactive voice used in captions and replies can just as easily be transferred and applied to any other social media platform.

\section{References}

[1] We Are Social. (2014, Jan 8). Global Digital Statistics 2014 [Presentation slides]. Retrieved from

http://www.slideshare.net/fullscreen/wearesocialsg/socialdigital-mobile-around-the-world-january-2014/1 Shaw, M. (2012, Feb). The state of social media. [PDF document]. Retrieved from http://www.comscore.com/content/download/13029/26760 1/file/The\%20State\%20of\%20Social\%20Media.pdf

[2] Singapore Polytechnic, Diploma in Media and Communication, Centre for Social Media. (2013). Impact of social media on youth well-being and happiness. Retrieved from http://www.spc4sm.com/latest-researchreport/

Singapore Parliament (2010, Mar 11). Parliamentary elections (amendment) bill. Retrieved from http://www.parliament.gov.sg/sites/default/files/100004.pdf

[3] Hodal, K. (2011, May 6). Singapore elections marked by online buzz of discontent. The Guardian. Retrieved from

http://www.theguardian.com/world/2011/may/06/singapore - elections-internet

Lim, P. (2011, Apr 22). Social media open up Singapore political debate. Agence France-Presse. Retrieved from http://www.google.com/hostednews/afp/article/ALeqM5j81 koyiJcwA5hUes8TTxXQ-

sQsag?docId=CNG.446a72f91fab21d9c39ad967bb39835f. 31

[4] Vergeer, M., Hermans, L., \& Sams, S. (2013). Online social networks and micro-blogging in political campaigning: The exploration of a new campaign tool and a new campaign style. Party Politics, 19(3), 477-501.

[5] Enli, G., \& Skogerbo, E. (2013). Personalized campaigns in party-centred politics: Twitter and Facebook as arenas for political communication. Information Communication \& Society, 16(5), 757-774.
[6] Experian. (2012, August 23). New study by Experian pinpoints rising social networks stars. Retrieved from http://press.experian.com/Singapore/Press-Release/newstudy-by-experian-pinpoints-rising-social-networksstars.aspx?\&p=1

[7] Piper Jaffray (2014). Taking stock with teens: A collaborative consumer insights project. Retrieved from http://www.piperjaffray.com/private/pdf/Taking_Stock_Te ach-In_Spring_2014.pdf

[8] McGraw, K. (2003). Political impressions: Formation and management. In D. Sears, L. Huddy, \& R. Jervis (Eds.), Oxford handbook of political psychology (pp. 394432). London: Oxford University Press.

[9] Stanyer, J. (2008). Elected representatives, online selfpreservation and the personal vote: Party, personality and webstyles in the United States and the United Kingdom. Information, Communication and Society, 11(30), 414-432.

[10] Gulati, G. (2004). Members of Congress and Presentation of Self on the World Wide Web. Harvard International Journal of Press/Politics, 9(1), 22-40.

[11] Golbeck, J., \& Grimes, J.M., \& Rogers, A. (2010). Twitter use by the US Congress. Journal of the American Society for Information Science and Technology, 61(8), 1612-1621.

[12] Van Aelst, P., Sheafer, T., \& Stanyer, J. (2012). The personalization of mediated political communication: A review of concepts, operationalizations and key findings. Journalism, 13(2), 203-220.

[13] Langer, A. (2010). The politicization of private persona: exceptional leaders or the new rule? The case of the United Kingdom and the Blair Effect. International Journal Of Press/Politics, 15(1), 60-76. doi:10.1177/1940161209351003

[14] Foo, J. Y. (2013, August 17). Selfie-centered. The New Paper. Retrieved from: http://www.tnp.sg/content/selfiecentred

[15] Langer, A. (2007). A historical exploration of the personalisation of politics in the print media: The British Prime Ministers (1945-1999). Parliamentary Affairs, 60(3), 371-387.

[16] McMillan, S. J. (2006). Exploring models of interactivity from multiple research traditions: Users, documents, and systems. Handbook of New Media, 205230.

[17] Sundar, S., Kalyanaraman, S., \& Brown, J. (2003). Explicating web site interactivity: Impression formation effects in political campaign sites. Communication Research, 30(1), 30-59.

[18] Stromer-Galley, J. (2000). Online interaction and why 
candidates avoid it. Journal of Communication, 50(4), 111132.

[19] Lee, E. J., \& Shin, S. Y. (2012). Are they talking to me? Cognitive and affective effects of interactivity in politicians' Twitter communication. Cyberpsychology, Behavior and Social Networking, 15(10), 515-520.

[20] Endres, D., \& Warnick, B. (2004). Text-based Interactivity in Candidate Campaign Web Sites: A Case Study from the 2002 Elections. Western Journal Of Communication, 68(3), 322-342.

[21] Horton, D., \& Wohl, R. R. (1956). Mass communication and para-social interaction: Observations on intimacy at a distance. Psychiatry, 19(3), 215-229.

[22] Miller, W. E., \& Shanks, J. M. (1996). The new American voter. Cambridge, MA: Harvard University Press.

[23] Marshall, T. R. (1984). Issues, personalities, and presidential primary voters. Social Science Quarterly (University Of Texas Press), 65(3), 750-760.

[24] Benoit, W. L., \& McHale, J. P. (2003). Presidential candidates' television spots and personal qualities. Southern Communication Journal, 68(4), 319-334.

[25] Hofstede, G. H. (2001). Culture's consequences: Comparing values, behaviors, institutions, and organizations across nations / Geert Hofstede. Thousand Oaks, Calif. : Sage Publications, c2001.

[26] Gorodnichenko, Y., \& Roland, G. (2012). Understanding the Individualism-Collectivism Cleavage and its Effects: Lessons from Cultural Psychology. In M. Aoki, T. Kuran, \& G. Roland (Eds.), Institutions and Comparative Economic Development (pp. 213-236). New York, NY: Palgrave Macmillan.

[27] Lau, R. R., \& Redlawsk, D. P. (2001). Advantages and Disadvantages of Cognitive Heuristics in Political Decision Making. American Journal of Political Science, 45(4), 951. 